\title{
Prevalence and characteristics of colonic adenoma in mainland China
}

\author{
Wandong Hong' \\ Lemei Dong' \\ Simon Stock ${ }^{2}$ \\ Zarrin Basharat ${ }^{3}$ \\ Maddalena Zippi ${ }^{4}$ \\ Mengtao Zhou ${ }^{5}$ \\ 'Department of Gastroenterology and \\ Hepatology, First Affiliated Hospital \\ of Wenzhou Medical University, \\ Wenzhou, China, ${ }^{2}$ Department of \\ Surgery, World Mate Emergency \\ Hospital, Battambang, Cambodia; \\ ${ }^{3}$ Jamil-ur-Rahman Center for Genome \\ Research, Dr Panjwani Center \\ for Molecular Medicine and Drug \\ Research, International Center for \\ Chemical and Biological Sciences, \\ University of Karachi, Karachi, \\ Pakistan; ${ }^{4}$ Unit of Gastroenterology \\ and Digestive Endoscopy, Sandro \\ Pertini Hospital, Rome, Italy; \\ ${ }^{5}$ Department of Surgery, First \\ Affiliated Hospital of Wenzhou \\ Medical University, Wenzhou, China
}

Correspondence: Wandong Hong Department of Gastroenterology and Hepatology, The First Affiliated Hospital of Wenzhou Medical University, Fanhaixi Road, Nanbaixiang Town, Ouhai District, Wenzhou City, Zhejiang Province, China

Tel +865775557 9l25

Fax +8657755579122

Email xhnk-hwd@163.com

Mengtao Zhou

Department of Surgery, The First

Affiliated Hospital of Wenzhou Medical

University, Nanbaixiang Town, Ouhai

District, Wenzhou City, Zhejiang

Province, China 325000, China

Tel +8657755579422

Fax +86 5775557 9I 22

Email studyzhoumengtao@sina.com
This article was published in the following Dove Press journal:

Cancer Management and Research

Background and aim: To investigate the prevalence and characteristics of colonic adenoma and advanced colonic adenoma in a large group of patients in mainland China.

Materials and methods: We conducted a cross-sectional study on patients who had undergone colonoscopy examination in a university hospital in mainland China. Colonic adenomas and advanced adenomas were recorded.

Results: The prevalence of polyps, adenoma, and advanced adenoma was $23.9 \%, 13.3 \%$, and $3.5 \%$, respectively. Age and sex were independent risk factors for the prevalence of adenoma and advanced adenoma. Polyp size was associated with an increased risk of both colonic adenoma (OR 1.50, 95\% CI 1.44-1.56) and advanced adenoma (OR 2.78, 95\% CI 2.55-3.03) after sex and age adjustment. Proximal colon polyps were a risk factor for adenoma (OR 1.41, 95\% CI $1.20-1.66)$ and also associated with a significant reduction (44\%) in risk of advanced adenoma (OR $0.56,95 \%$ CI 0.36-0.86) compared to distal colon adenoma after sex and age adjustment. A screening indication was associated with a statistically significant decrease in the odds of prevalence of adenoma (OR 0.90, 95\% CI 0.81-0.99) and advanced adenoma (OR 0.72, 95\% CI 0.59-0.88) compared to a no-screening indication.

Conclusion: The overall prevalence of adenoma was low in mainland China. It exhibited a varied pattern with respect to age and sex. Polyp size was a risk factor for both colonic adenoma and its transition to advanced adenoma. Proximal colon polyps were a risk factor for adenoma, but a protective factor for advanced adenoma compared to distal colon adenoma.

Keywords: colonic adenoma, advanced adenoma, colonic polyps, colonoscopy, epidemiology

\section{Introduction}

Colorectal carcinoma is the second-leading cause of cancer-related death in the Western world. ${ }^{1}$ In China, colorectal cancer is the sixth-most common cancer and the fifth-leading cause of death. ${ }^{2}$ Colorectal carcinoma usually arises from an adenomatous polyp. Better understanding of the prevalence of adenomas would be helpful to estimate cancer risk and to clarify the efficacy of a colorectal cancer-screening program. ${ }^{3}$ Colorectal cancer screening can reduce mortality from colorectal cancer, due to early detection and hence removal of premalignant adenoma or localized cancer. Evolving data suggest the prevalence of adenoma may predict subsequent colorectal cancer risk after performing colonoscopy. ${ }^{4}$ The prevalence of colonic adenoma increases with age, and varies with geography and ethnicity. It has been estimated that $>20 \%$ of Western populations have colonic adenoma, while a lower rate, ie, $(8.13 \%-16.5 \%)^{3,6}$ has been recorded in Asia. There are minimal data on 
the prevalence of adenoma stratified with age and sex from China. A decade ago, Liu et $\mathrm{al}^{7}$ and Sung et $\mathrm{al}^{1}$ reported the prevalence of advanced colonic polyps in Chinese populations in Taiwan and Hong Kong, respectively. However, to the best of our knowledge, information about the exact prevalence of colonic adenoma and advanced adenoma in mainland China is limited.

Better understanding of the characteristics of colonic adenoma might be helpful for adenoma management and colonoscopy surveillance after removal. Hassan et al ${ }^{8}$ suggested that extremely low prevalence of advanced neoplasia in diminutive $(<0.5 \mathrm{~cm})$ colonic polyps, especially in the distal colon, would support the safety of a resect-and-discard strategy. Current guidelines endorse a shorter interval for surveillance of colonic adenoma, ie, $<1 \mathrm{~cm}$ ( $<3$ years) compared to patients with one or two tubular adenomas, ie, $<1$ cm (5-10 years). ${ }^{9}$ In addition, adenoma location can be an important determinant of the type of screening test selected, because sigmoidoscopy would be less effective in populations that have higher rates of proximal adenoma. ${ }^{10}$ For these reasons, this study aimed to investigate the prevalence and characteristics of colonic adenoma and advanced adenoma in a large group of patients in mainland China.

\section{Materials and methods}

\section{Study design and subject selection}

We conducted a cross-sectional study in the First Affiliated Hospital of Wenzhou Medical University in mainland China. All subjects who had received a colonoscopy between October 2013 and December 2014 were eligible for inclusion in this study. ${ }^{11}$ This study protocol was approved by the ethics committee of the hospital, the study was performed according to the principles expressed in the Declaration of Helsinki, and written informed consent was obtained from all subjects.

\section{Inclusion and exclusion criteria}

Inclusion criteria were age $\geq 13$ years, indications for symptomatic patients, or screening colonoscopy in asymptomatic individuals. A screening examination ${ }^{12}$ was defined as a colonoscopy for which there was no surveillance or diagnostic indication and individuals had no symptoms of lower gastrointestinal pathology. ${ }^{13}$ Exclusion criteria were repeat colonoscopy examination within 1 year (for which only the most recent colonoscopy examination was included in our study), incomplete colonoscopy examination, inadequate bowel preparation, therapeutic colonoscopy, colon cancer, prior colonic resection, and unavailability of polyp details. ${ }^{14}$

\section{Variables and outcome measurement}

Collected data included indication for colonoscopy, completeness of colonoscopy examination, quality of bowel preparation, age, sex, histological results, distribution, and size and number of polyps. A complete colonoscopy was defined as either intubation of the ileum or identification of the appendiceal orifice and ileocecal valve..$^{15}$ The definition of bowel-preparation quality followed previous work. ${ }^{9,16}$ Adequate bowel preparation was defined as "excellent" or "good" quality of bowel preparation. ${ }^{9}$ Age was parsed into a categorical variable with seven groups: $\leq 39,40-44,45-49$, $50-54,55-59,60-64$, and $\geq 65$ years. Colorectal adenomas were defined as one or more histology-confirmed adenomas present on colonoscopy, irrespective of size or location. ${ }^{17}$ Advanced adenoma was defined as adenoma $>1 \mathrm{~cm}$ or adenoma with villoglandular histology or high-grade dysplasia. ${ }^{17}$ Colonic adenoma was separated by location into distal (descending colon, sigmoid colon, and rectum), proximal (cecum, ascending colon, and transverse colon) and bilateral (distal and proximal sections of the colon) regions. ${ }^{18}$ All polyps detected at colonoscopy were grouped into size categories $(\leq 0.5,0.6-0.9$, and $\geq 1.0 \mathrm{~cm})$ based on their endoscopic measurement by comparison with the known diameter of open biopsy forceps. ${ }^{8,18,19}$ The number of polyps was parsed into a categorical variable (one vs two or more).

Outcomes measured were prevalence and characteristics (distribution, size, and number) of colonic polyps, adenoma, and advanced adenoma. Polyp prevalence was defined as the number of colonoscopies in which one or more polyps had been detected divided by the total number of colonoscopies. Adenoma prevalence (synonymous with adenoma-detection rate) was defined as the number of colonoscopies in which one or more adenoma had been detected divided by the total number of colonoscopies. ${ }^{18}$ Advanced adenoma prevalence was defined as the number of colonoscopies in which one or more advanced adenoma were detected divided by the total number of colonoscopies.

\section{Statistical analysis}

Categorical values are given as count and proportions, and were compared by $\chi^{2}$-tests. Continuous values are expressed as means $\pm \mathrm{SD}$, and were compared using independent-sample $t$-tests. Linear trends of categorical and continuous variables was tested by a Royston extension of the Cochran-Armitage test ${ }^{20}$ and nonparametric Wilcoxon rank-sum tests, ${ }^{21}$ respectively. Both crude and age-standardized prevalence of adenoma and advanced adenoma were reported when comparing sex difference. Age-standardized prevalence was calculated using the 
direct standardization method using the world population standard (2000-2025), reported by the World Health Organization. ${ }^{22}$

Stratified (subgroup) analysis was performed according to colonoscopy indication (asymptomatic individuals with screening colonoscopy vs symptomatic patients). Multivariate logistic regression analysis was used to evaluate the risk factor for colonic adenoma and advanced adenoma. Similar to Lieberman et al, ${ }^{10}$ we included colonoscopy indication (screening vs no screening) as a covariate in multivariate logistic regression. OR was calculated with 95\% CI. Twosided $P$-values $<0.05$ were considered significant.

\section{Results \\ Baseline characteristics}

As shown in Figure 1, 26,352 colonoscopy examinations were performed during October 2013-December 2014 in the hospital. A total of 17,134 subjects (with males being $57.9 \%$ ) were enrolled in this study. The prevalence of polyps, adenoma, and advanced adenoma was 23.9\% (4,098 of 17,134$), 13.3 \%$ (2,287 of 17,134), and 3.5\% (592 of 17,134), respectively (Figure 1). Patients with polyps were more likely to be older (mean age $54.5 \pm 12.1$ vs $47.2 \pm 12.4$ years, $P<0.001)$ and male $(68.2 \%$ vs $54.6 \%, P<0.001)$ than

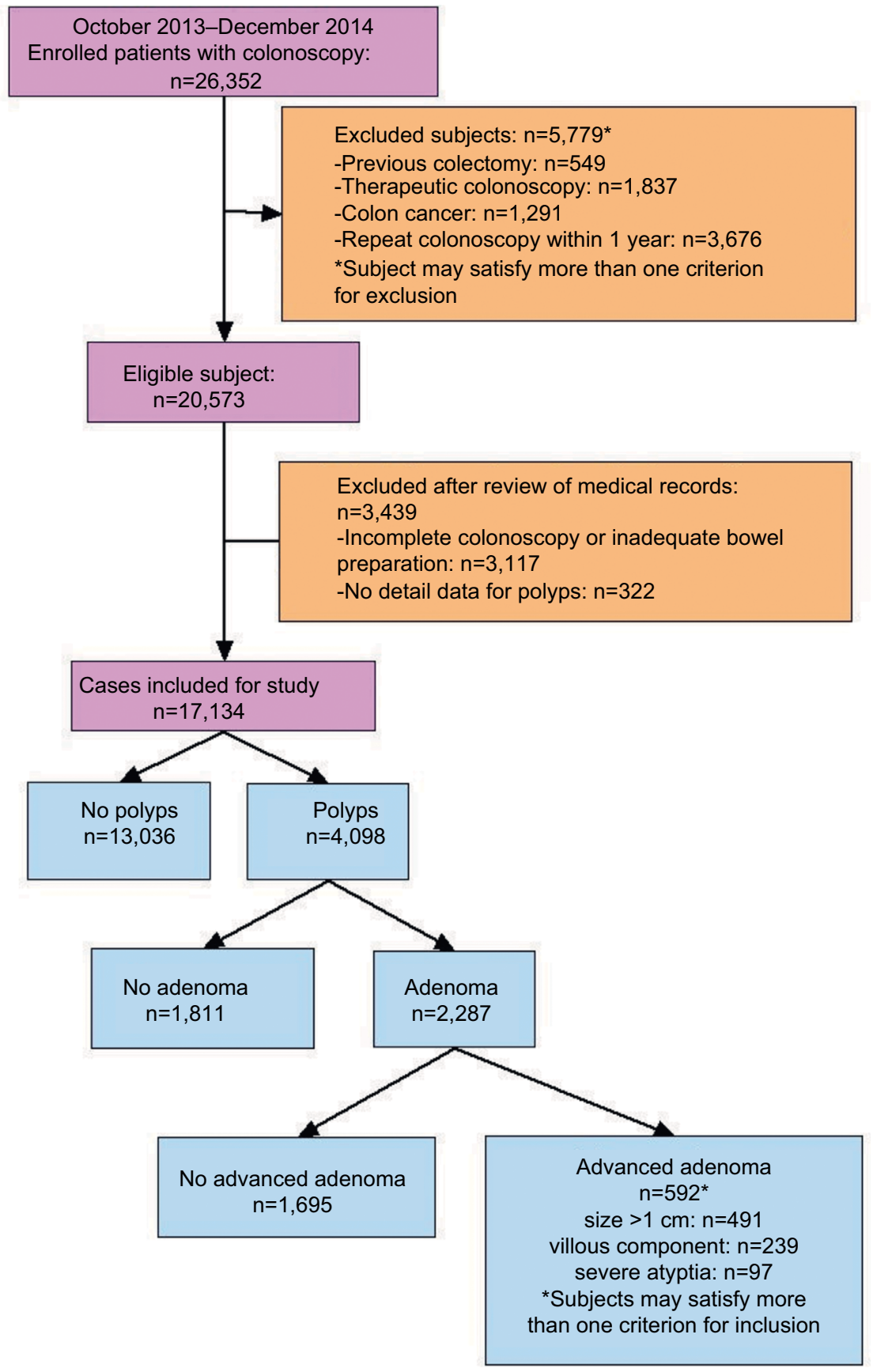

Figure I Flow diagram of patients included in this study and baseline characteristics. 
those without polyps. Of patients with advanced adenoma, most (491 of 592, 82.9\%) had polyps $>1 \mathrm{~cm}$ (Figure 1). Distribution of sex and age-groups among 17,134 patients in different subgroups (screening colonoscopy vs symptomatic patients) is shown in Figure 2. The proportion of elderly patients ( $\geq 65$ years) who underwent colonoscopy was $12.1 \%(2,067$ of 17,134$)$, irrespective of sex or colonoscopy indication. As shown in Figure 3, the proportion of asymptomatic individuals with screening colonoscopy was $28.9 \%(4,950$ of 17,134$)$. The most common colonoscopy indication for symptomatic patients was functional bowel disorder, ie, $30.4 \%(5,215$ of 17,134$)$, followed by patients with personal history of polyps $(1,783$ of $17,134,10.4 \%)$, gastrointestinal bleeding $(1,571$ of $17,134,9.2 \%)$, and diarrhea $(1,528$ of $17,134,8.9 \%)$.

\section{Prevalence of adenoma and association with sex and age}

The overall adenoma prevalence rose across all age categories, reaching a peak at $\geq 65$ years of age: $4.6 \%, 8.2 \%$, $10.6 \%, 15.8 \%, 18.3 \%, 20.7 \%$, and $27.3 \%$ in age-groups $\leq 39$,
$40-44,45-49,50-54,55-59,60-64$, and $\geq 65$ years. These findings indicate a greater increase in age being associated with increased adenoma prevalence (test for trend, $P<0.001$; Figure 4). For all age categories combined, crude adenoma prevalence was higher in men than in women $(15.7 \%$ vs $10.1 \%, P<0.001)$. Age-standardized adenoma prevalence was also higher in men than in women $(10.3 \%$ vs $7.0 \%)$. When stratified by sex, the increase in adenoma with age was similar for both men and women. Among men, crude prevalence increased from $5.1 \%$ at $\leq 39$ years of age to a high of $29.8 \%$ by $\geq 65$ years of age (test for trend, $P<0.001$ ). Among women, the crude prevalence increased from 3.7\% in patients $\leq 39$ years of age to $23.8 \%$ in $\geq 65$ years of age (test for trend, $P<0.001$ ).

When stratified by colonoscopy indication, the relationship between prevalence of adenoma and association with sex and age was similar in different subgroups (Figure 5). Multivariate logistic regression analysis indicated that sex (males, OR 1.73, 95\% CI 1.57-1.90; $P<0.001$ ) and age (per 5 years, OR 4.54, 95\% CI 4.08-5.06; $P<0.001$ ) was a risk factor independently associated with increased prevalence
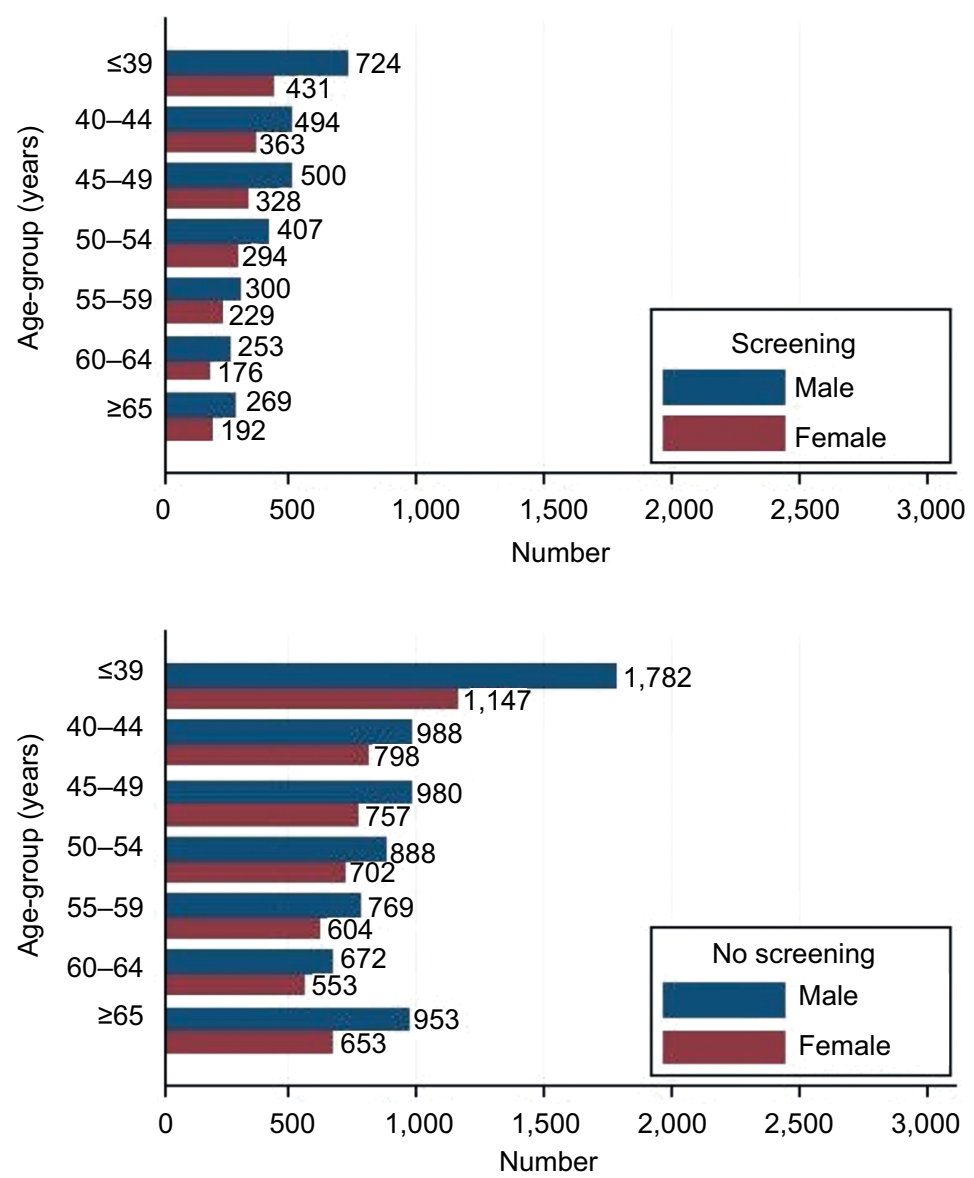

Figure 2 Distribution of sex and age-groups among 17,134 patients in different subgroups (screening colonoscopy vs no-screening patients). 


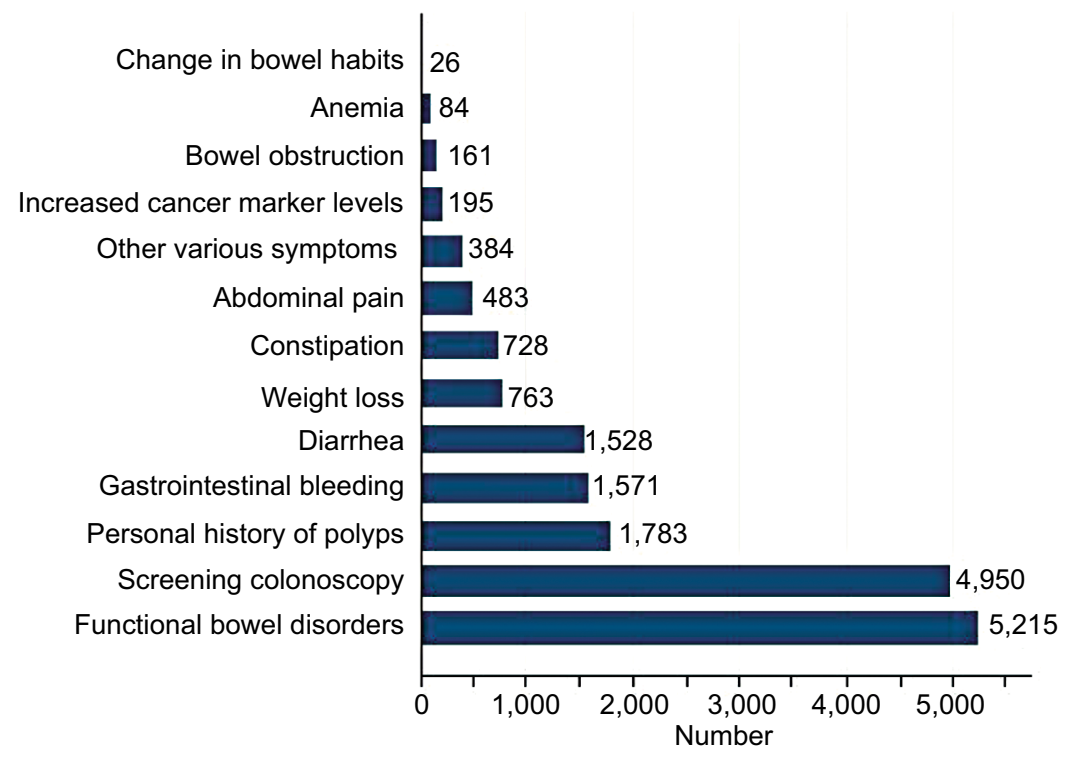

Figure 3 Indication for colonoscopy among 17,134 patients.

Note: Subjects may satisfy more than one indication for colonoscopy among symptomatic patients.

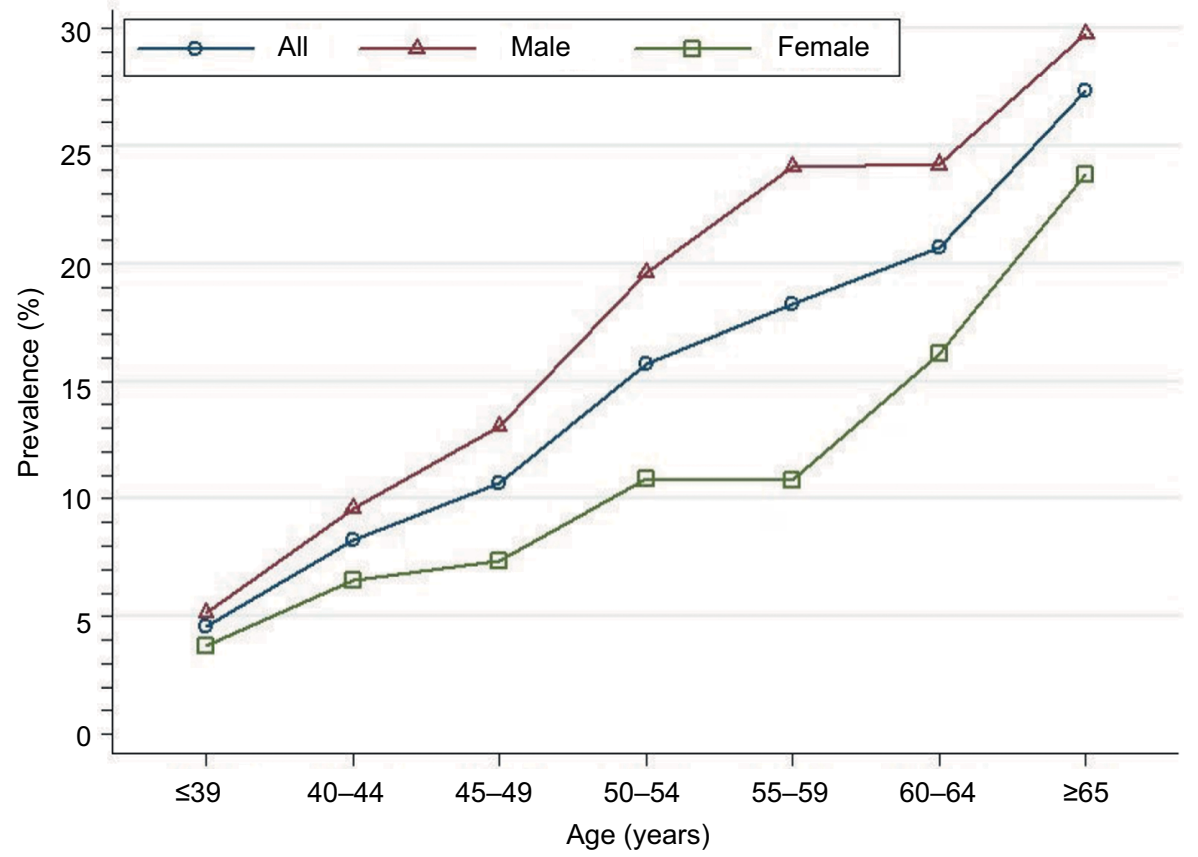

Figure 4 Prevalence of colonic adenoma stratified by sex and age among 17,134 patients.

of adenoma. A screening indication was associated with a statistically significant $10 \%$ reduction in adenoma-prevalence odds compared with a colonoscopy indication for symptomatic patients (OR 0.90, 95\% CI 0.81-0.99; $P=0.043$ ).

\section{Prevalence of advanced adenoma and associations by sex and age}

Overall advanced-adenoma prevalence rose across all seven age categories, reaching a peak at $\geq 65$ years: $0.86 \%, 1.95 \%$,
$2.51 \%, 4.01 \%, 4.57 \%$, and $7.98 \%$ for age-groups $\leq 39,40-44$, $45-49,50-54,55-59,60-64$, and $\geq 65$ years, respectively. This indicates that increased age is associated with increased advanced-adenoma prevalence (test for trend, $P<0.001$; Figure 6). For all age-groups combined, crude advancedadenoma prevalence was higher in men than women (4.2\% vs $2.4 \%$, respectively; $P<0.001)$. Age-standardized advancedadenoma prevalence was also higher in men than women $(2.5 \%$ vs $1.6 \%)$. When stratified by sex, the increase with age 
was similar for both men and women. Among men, crude prevalence increased from $0.88 \%$ at $\leq 39$ years of age to a high of $9.08 \%$ by $\geq 65$ years of age (test for trend, $P<0.001$ ). Among women, crude prevalence increased from $0.82 \%$ in
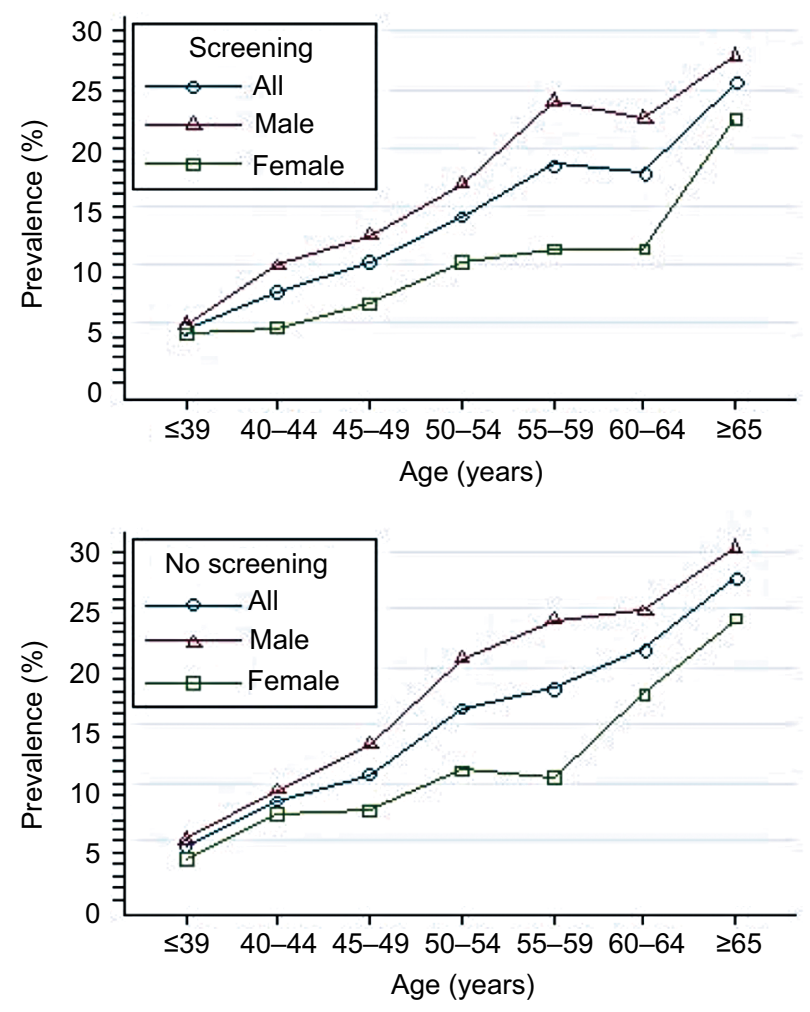

Figure 5 Prevalence of colonic adenoma stratified by sex and age in different subgroups (screening colonoscopy vs symptomatic patients). patients $\leq 39$ years of age to a high of $6.39 \%$ by $\geq 65$ years of age (test for trend, $P<0.001$ ).

When stratified by colonoscopy indication, the relationship between prevalence of advanced adenoma and association with sex and age was similar in different subgroups (Figure 7). Multivariate logistic regression analysis indicated that sex (OR 1.81, 95\% CI 1.51-2.16; $P<0.001$ ) and age (per 5 years; OR 4.93, 95\% CI 4.02-6.02; $P<0.001$ ) were independently associated with increased prevalence of advanced adenoma. A screening indication was associated with a statistically significant $28 \%$ reduction in advancedprevalence adenoma odds compared with a colonoscopy indication for symptomatic patients (OR $0.72,95 \% \mathrm{CI}$ $0.59-0.88 ; P=0.001)$.

\section{Comparison between adenomatous polyps and nonadenomatous polyps}

As shown in Table 1, a pathological diagnosis of colonic adenoma was found in $55.8 \%(2,287$ of 4,098$)$ of patients with colonic polyps. No difference was observed in patients with or without adenomatous polyps with respect to sex. However, patients with adenomatous polyps were older than those without adenomatous polyps ( 56.1 years vs 52.5 years, $P<0.001$ ). The proportion ( 749 of $2,287,47.3 \%$ ) of patients with polyps $\geq 2 \mathrm{~cm}$ was higher in patients with adenomatous polyps than patients without (343 of $1,811,18.9 \%, P<0.001$ ). The mean size of polyps was greater in patients with adenomatous polyps than patients without adenomatous polyps $(0.71 \mathrm{~cm}$ vs $0.40 \mathrm{~cm}, P<0.001)$.

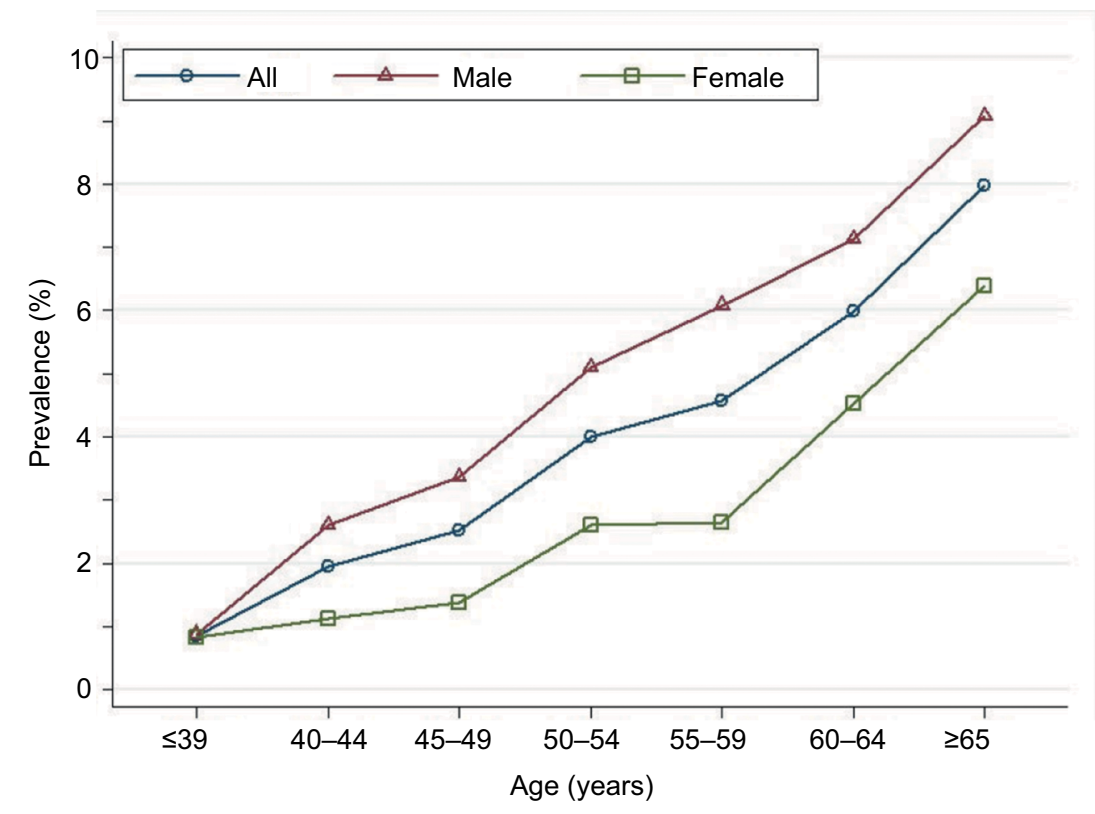

Figure 6 Prevalence of colonic advanced adenoma stratified by sex and age among 17,134 patients. 

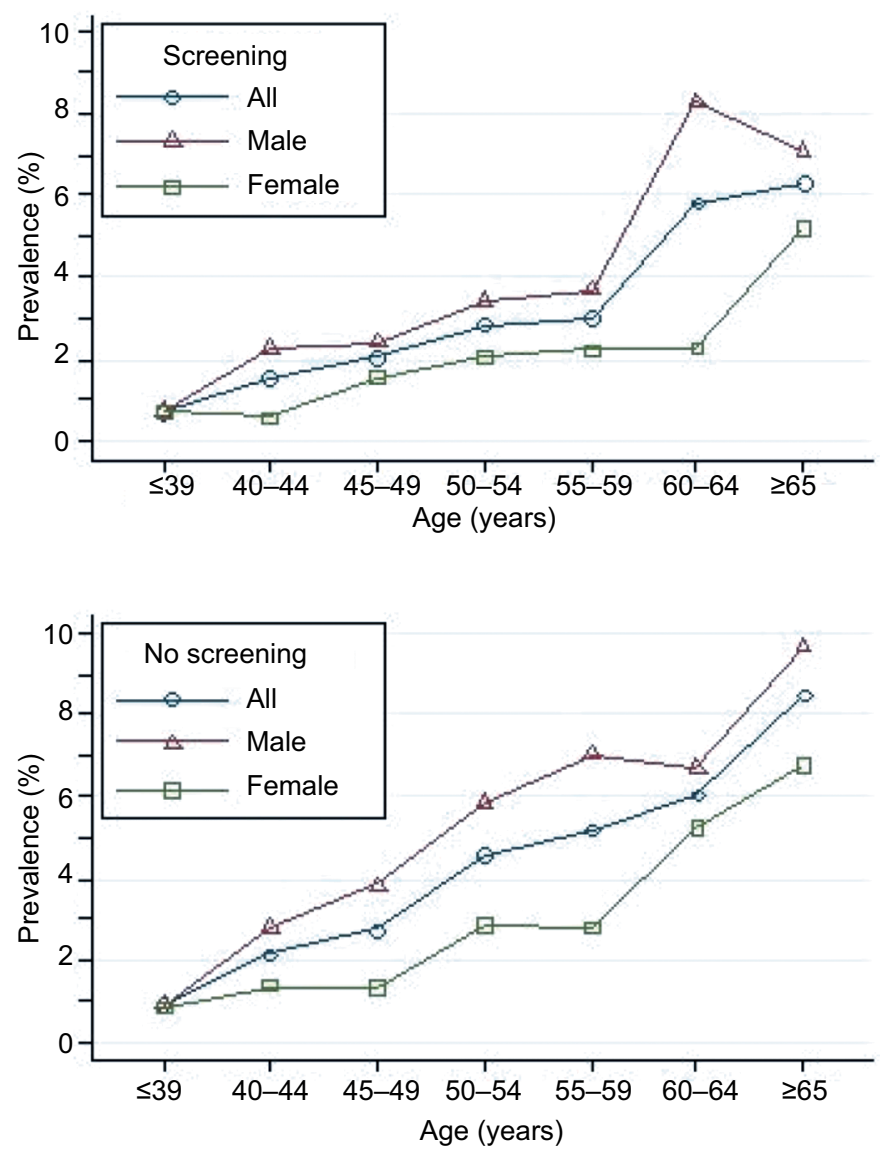

Figure 7 Prevalence of colonic advanced adenoma stratified by sex and age in different subgroups (screening colonoscopy vs no-screening patients).

Table I Comparison of sex, age, number, size, and location of polyps among patients with or without adenomatous polyps in all screening and no-screening colonoscopy $(n=4,098)$

\begin{tabular}{|c|c|c|c|}
\hline Variables & $\begin{array}{l}\text { Adenomatous } \\
\text { polyps }(n=2,287)\end{array}$ & $\begin{array}{l}\text { Nonadenomatous } \\
\text { polyps }(n=I, 8 I I)\end{array}$ & $P$-value \\
\hline Sex & & & 0.825 \\
\hline Women & 731 (56.1\%) & $573(43.9 \%)$ & \\
\hline Men & I,556 (55.7\%) & I,238 (44.3\%) & \\
\hline Mean age (years) & $56.1 \pm 11.9$ & $52.5 \pm 12.0$ & $<0.001$ \\
\hline Number of polyps & & & $<0.001$ \\
\hline I & I,538 (5।.2\%) & $\mathrm{I}, 468$ (48.8\%) & \\
\hline$\geq 2$ & $749(68.6 \%)$ & $343(31.4 \%)$ & \\
\hline Mean polyp size $(\mathrm{cm})$ & $0.7 I \pm 0.57$ & $0.40 \pm 0.14$ & $<0.001$ \\
\hline Polyp size (cm) & & & $<0.001$ \\
\hline$\leq 0.5$ & $\mathrm{I}, 250(44.6 \%)$ & I,553 (55.4\%) & \\
\hline $0.6-0.9$ & $546(68.0 \%)$ & 257 (32.0\%) & \\
\hline$\geq 1.0$ & 491 (99.8\%) & I (0.2\%) & \\
\hline Location of polyps & & & $<0.001$ \\
\hline Distal colon & $\mathrm{I}, 356(5 \mathrm{I} .8 \%)$ & I,263 (48.2\%) & \\
\hline Proximal colon & $566(58.8 \%)$ & $396(41.2 \%)$ & \\
\hline Bilateral colon & $365(70.6 \%)$ & $152(29.4 \%)$ & \\
\hline
\end{tabular}


In addition, the proportion of adenomatous polyps was $44.6 \%, 68.0 \%$, and $99.8 \%$ in patient groups with $\leq 0.5$, $0.6-0.9$, and $\geq 1 \mathrm{~cm}$ polyps, respectively (Table 1 ). This means that patients with larger polyps had a higher proportion of adenoma $(P<0.001)$. With respect to location in the colon, most adenomas were located in the distal colon $(1,356$ of $2,287,59.3 \%$ ), followed by proximal (566 of $2287,24.7 \%$ ) and bilateral colon (365 of 2,287, 16.0\%). However, a higher proportion of polyps were adenomatous in the bilateral
(70.6\%) and proximal (58.8\%) colon compared to the distal colon $(51.8 \%, P<0.001$; Table 1$)$.

When stratified by colonoscopy indication, adenomatous polyps and nonadenomatous polyps were similar in different subgroups (Tables 2 and 3). Multivariate logistic regression analysis indicated that polyp size (OR 1.50, 95\% CI 1.44-1.56 for 1 millimeter change in polyp size; $P<0.001)$ and location in the proximal colon (OR 1.41, 95\% CI 1.20-1.66; $P<0.001$ ), but not colonoscopy indication (OR 1.00, 95\% CI 0.86-1.68;

Table 2 Comparison of sex, age, number, size, and location of polyps among patients with or without adenomatous polyps in screening colonoscopy $(n=I, \mid 40)$

\begin{tabular}{|c|c|c|c|}
\hline & $\begin{array}{l}\text { Adenomatous } \\
\text { polyps }(n=596)\end{array}$ & $\begin{array}{l}\text { Nonadenomatous } \\
\text { polyps }(n=544)\end{array}$ & $P$-value \\
\hline Sex & & & 0.155 \\
\hline Women & 175 (49.2\%) & I8I (50.8\%) & \\
\hline Men & $421(53.7 \%)$ & $363(46.3 \%)$ & \\
\hline Mean age (years) & $54.5 \pm 11.2$ & $51.9 \pm 11.6$ & $<0.001$ \\
\hline Number of polyps & & & $<0.001$ \\
\hline 1 & 426 (49.0\%) & $443(51.0 \%)$ & \\
\hline$\geq 2$ & I 70 (62.7\%) & 101 (37.3\%) & \\
\hline Mean polyp size $(\mathrm{cm})$ & $0.63 \pm 0.50$ & $0.38 \pm 0.14$ & $<0.001$ \\
\hline Polyp size $(\mathrm{cm})$ & & & $<0.001$ \\
\hline$\leq 0.5$ & 361 (42.7\%) & $484(57.3 \%)$ & \\
\hline $0.6-0.9$ & $134(69.1 \%)$ & $60(30.9 \%)$ & \\
\hline$\geq 1.0$ & 101 (100\%) & 0 & \\
\hline Location of polyps & & & $<0.001$ \\
\hline Distal colon & $353(48.1 \%)$ & $381(51.9 \%)$ & \\
\hline Proximal colon & I6I (57.3\%) & $120(42.7 \%)$ & \\
\hline Bilateral colon & 82 (65.6\%) & 43 (34.4\%) & \\
\hline
\end{tabular}

Table 3 Comparison of sex, age, number, size, and location of polyps among patients with or without adenomatous polyps in noscreening colonoscopy $(n=2,958)$

\begin{tabular}{|c|c|c|c|}
\hline & $\begin{array}{l}\text { Adenomatous } \\
\text { polyps }(n=I, 69 I)\end{array}$ & $\begin{array}{l}\text { Nonadenomatous } \\
\text { polyps }(n=1,267)\end{array}$ & $P$-value \\
\hline Sex & & & 0.263 \\
\hline Women & $556(58.7 \%)$ & $392(41.3 \%)$ & \\
\hline Men & $\mathrm{I}, \mathrm{I} 35$ (56.5\%) & 875 (43.5\%) & \\
\hline Mean age (years) & $56.7 \pm 12.0$ & $52.8 \pm 12.1$ & $<0.001$ \\
\hline Number of polyps & & & $<0.001$ \\
\hline I & I, I I 2 (52.0\%) & $\mathrm{I}, 025$ (48.0\%) & \\
\hline$\geq 2$ & 579 (70.5\%) & $242(29.5 \%)$ & \\
\hline Mean polyp size $(\mathrm{cm})$ & $0.74 \pm 60$ & $0.40 \pm 0.15$ & $<0.001$ \\
\hline Polyp size (cm) & & & $<0.001$ \\
\hline$\leq 0.5$ & 889 (45.4\%) & I,069 (54.6\%) & \\
\hline $0.6-0.9$ & $412(67.7 \%)$ & $197(32.3 \%)$ & \\
\hline$\geq 1.0$ & $390(99.7 \%)$ & I (0.3\%) & \\
\hline Location of polyps & & & $<0.001$ \\
\hline Distal colon & $\mathrm{I}, 003$ (53.2\%) & 882 (46.8\%) & \\
\hline Proximal colon & 405 (59.5\%) & 276 (40.5\%) & \\
\hline Bilateral colon & 283 (72.2\%) & 109 (27.8\%) & \\
\hline
\end{tabular}


$P=0.959)$ were associated with an increased risk of adenomas after adjustment for sex and age.

\section{Comparison between advanced adenomatous polyps and unadvanced adenomatous polyps}

As shown in Table 4, there was no difference between patients with or without advanced adenomatous polyps with respect to sex. However, patients with advanced adenomatous polyps were older than those without ( 57.6 vs 55.6 years, $P<0.001$ ). The proportion (298 of 592, 50.3\%) of those with two or more polyps was higher in patients with advanced adenomatous polyps than those without (451 of 1,695 , $26.6 \% ; P<0.001)$. Mean polyps size was greater in patients with adenomatous polyps than those without ( 1.39 vs 0.47 $\mathrm{cm}, P<0.001)$. In addition, the proportion of advanced-stage adenomatous polyps was $3.8 \%, 9.7 \%$, and $100 \%$ in patient groups with polyps $\leq 0.5,0.6-0.9$, and $\geq 1 \mathrm{~cm}$ respectively (Table 4). This means that a higher proportion of patients with bigger adenomas had advanced adenoma $(P<0.001)$. With respective to location in the colon, advanced adenoma was located more in the distal colon (365 of 592, 61.7\%), followed by the bilateral colon (153 of 592, 25.8\%) and the proximal colon (74 of 592, 12.5\%). A higher proportion of adenoma was advanced adenoma in the bilateral (41.9\%) and distal $(26.9 \%)$ colon compared to the proximal (13.1\%) colon $(P<0.001)$ (Table 4$)$.

When stratified by colonoscopy indication, adenomatous polyp and unadvanced adenomatous polyp numbers were similar in different subgroups (Tables 5 and 6). Multivariate logistic regression analysis indicated that after adjustment for sex and age, polyp size (OR 2.78, 95\% CI 2.55-3.03; $P<0.001)$ was associated with increased risk of advanced adenoma, while location in the proximal colon (OR 0.56, 95\% CI $0.36-0.86 ; P=0.009)$ was associated with a significant reduction (44\%) in advanced-adenoma risk compared to adenoma in the distal colon. As expected, there was no

Table 5 Comparison of sex, age, number, size, and location of polyps among patients with or without advanced adenomatous polyps in screening colonoscopy $(n=596)$

\begin{tabular}{|c|c|c|c|}
\hline & $\begin{array}{l}\text { Advanced } \\
\text { adenoma } \\
(n=\mid 28)\end{array}$ & $\begin{array}{l}\text { Unadvanced } \\
\text { adenoma } \\
(n=468)\end{array}$ & $P$-value \\
\hline Sex & & & $0.57 \mid$ \\
\hline Women & $35(20.0 \%)$ & 140 (80.0\%) & \\
\hline Men & $93(22.1 \%)$ & $328(77.9 \%)$ & \\
\hline Mean age (years) & $56.2 \pm 11.2$ & $54.0 \pm 11.1$ & 0.049 \\
\hline Number of polyps & & & $<0.001$ \\
\hline 1 & $62(14.6 \%)$ & $364(85.4 \%)$ & \\
\hline$\geq 2$ & $66(38.8 \%)$ & $104(61.2 \%)$ & \\
\hline Mean size of polyps $(\mathrm{cm})$ & $1.26 \pm 0.74$ & $0.45 \pm 0.15$ & $<0.001$ \\
\hline Size of polyps $(\mathrm{cm})$ & & & $<0.001$ \\
\hline$\leq 0.5$ & $12(3.3 \%)$ & 349 (96.7\%) & \\
\hline $0.6-0.9$ & 15 (11.2\%) & $119(88.8 \%)$ & \\
\hline$\geq 1.0$ & $101(100.0 \%)$ & 0 & \\
\hline Location of polyps & & & $<0.001$ \\
\hline Distal colon & $8 \mathrm{I}(23.0 \%)$ & $272(77.0 \%)$ & \\
\hline Proximal colon & $16(10.0 \%)$ & 145 (90\%) & \\
\hline Bilateral colon & $31(37.8 \%)$ & $51(62.2 \%)$ & \\
\hline
\end{tabular}

Table 4 Comparison of sex, age, number, size, and location of polyps among patients with or without advanced adenomatous polyps in screening and no-screening colonoscopy $(n=2,287)$

\begin{tabular}{|c|c|c|c|}
\hline & $\begin{array}{l}\text { Advanced } \\
\text { adenoma }(n=592)\end{array}$ & $\begin{array}{l}\text { Unadvanced } \\
\text { adenoma }(n=I, 695)\end{array}$ & $P$-value \\
\hline Sex & & & 0.176 \\
\hline Women & $176(24.1 \%)$ & $555(75.9 \%)$ & \\
\hline Men & $416(26.7 \%)$ & $\mathrm{I}, \mathrm{I} 40(73.3 \%)$ & \\
\hline Mean age (years) & $57.6 \pm 11.9$ & $55.6 \pm 11.8$ & $<0.001$ \\
\hline Number of polyps & & & $<0.001$ \\
\hline I & $294(19.1 \%)$ & $1,244(80.9 \%)$ & \\
\hline$\geq 2$ & $298(39.8 \%)$ & $45 I(60.2 \%)$ & \\
\hline Mean polyp size $(\mathrm{cm})$ & $1.39 \pm 0.76$ & $0.47 \pm 0.16$ & $<0.001$ \\
\hline Polyp size $(\mathrm{cm})$ & & & $<0.001$ \\
\hline$\leq 0.5$ & 48 (3.8\%) & I,202 (96.2\%) & \\
\hline $0.6-0.9$ & $53(9.7 \%)$ & $493(90.3 \%)$ & \\
\hline$\geq 1.0$ & $491(100 \%)$ & 0 & \\
\hline Location of polyps & & & $<0.001$ \\
\hline Distal colon & 365 (26.9\%) & 991 (73.1\%) & \\
\hline Proximal colon & $74(13.1 \%)$ & $492(86.9 \%)$ & \\
\hline Bilateral colon & $153(41.9 \%)$ & $212(58.1 \%)$ & \\
\hline
\end{tabular}


Table 6 Comparison of sex, age, number, size, and location of polyps among patients with or without advanced adenomatous polyps in no-screening colonoscopy $(n=I, 69 I)$

\begin{tabular}{llll}
\hline & $\begin{array}{l}\text { Advanced } \\
\text { adenoma } \\
(\mathbf{n = 4 6 4 )}\end{array}$ & $\begin{array}{l}\text { Unadvanced } \\
\text { adenoma } \\
(\mathbf{n = 1}, \mathbf{2 2 7})\end{array}$ & P-value \\
\hline Sex & $141(25.4 \%)$ & $415(74.6 \%)$ & 0.180 \\
Women & $323(28.5 \%)$ & $812(71.5 \%)$ & \\
Men & $58.0 \pm 12.1$ & $56.2 \pm 12.0$ & 0.006 \\
Mean age (years) & & & $<0.001$ \\
Number of polyps & $232(20.9 \%)$ & $880(79.1 \%)$ & \\
I & $232(40.1 \%)$ & $347(59.9 \%)$ & \\
$\geq 2$ & $1.43 \pm 0.76$ & $0.48 \pm 0.16$ & $<0.001$ \\
Mean polyp size (cm) & & & $<0.001$ \\
Polyp size (cm) & $36(4.1 \%)$ & $853(95.9 \%)$ & \\
$\leq 0.5$ & $38(9.2 \%)$ & $374(90.8 \%)$ & \\
$0.6-0.9$ & $390(100 \%)$ & 0 & \\
$\geq 1.0$ & & & $<0.001$ \\
Location of polyps & $284(28.3 \%)$ & $719(71.7 \%)$ & \\
Distal colon & $58(14.3 \%)$ & $347(85.7 \%)$ & \\
Proximal colon & $122(43.1 \%)$ & $161(56.9 \%)$ & \\
Bilateral colon & & & \\
\hline
\end{tabular}

statistical relationship between colonoscopy indication (OR $1.20,95 \%$ CI $0.82-1.75 ; P=0.365)$ and risk of advanced adenoma.

\section{Discussion}

The outcomes of the present study showed that the prevalence of polyps, adenoma, and advanced adenoma was $23.9 \%$, $13.3 \%$ and $3.5 \%$, respectively, increased age and male sex was associated with increased adenoma and advanced-adenoma prevalence, polyp size and location in the proximal colon were associated with an increased risk of adenomas after adjustment for sex and age, polyp size was associated with an increased risk of advanced adenoma, while location in the proximal colon was associated with a significant reduction in the risk of advanced adenoma compared to the distal colon region after adjustment for sex and age, and screening indication was associated with a statistically significant decrease in the odds of prevalence of adenoma and advanced adenoma when compared with a colonoscopy indication for symptomatic patients.

The prevalence of colonic adenoma varies worldwide in different populations. ${ }^{5}$ The overall prevalence of colonic adenoma in this study was $13.3 \%$ (Figure 1), which was comparable to recent reports for Arabs $(8.1 \%)^{3}$ and Hispanics $(16.8 \%) .{ }^{23}$ However, it was significantly lower than that of the US populace $(20.2 \%-31 \%))^{4,13,18}$ Similarly, the overall prevalence of colonic advanced adenoma in this study was $3.5 \%$, which was comparable to reports from
Taiwan (3.3\%). ${ }^{7}$ Almadi et $\mathrm{al}^{3}$ reported a low prevalence of colonic advanced adenoma (0.5\%) in Saudi Arabia. Regula et al $(5.9 \%)^{24}$ and Strul et al $(6.7 \%)^{25}$ also observed a higher prevalence of colonic advanced adenoma in the US. These differences might have been due to differences in race, genetic predisposition, lifestyle (smoking, alcohol consumption), dietary habits (meat consumption), and proportion of elderly people in the studied populace who underwent colonoscopy examination, as the prevalence of colonic adenoma is agedependent. ${ }^{4,10}$ Evidence from the literature also indicates that the average daily total dietary fiber intake among Chinese adults is higher than that of Western countries, such as the US and France. ${ }^{14}$ It has been reported that a high-fiber dietary pattern and subsequent consistent production of short-chain fatty acids and healthy gut microbiota are associated with a reduced risk of advanced colorectal adenoma. ${ }^{26}$ In addition, the proportion of elderly patients (aged $\geq 65$ years) who underwent colonoscopy was $12.1 \%$ sex or colonoscopy indication (Figure 2), which was lower compared to other studies (29\%-30\%). ${ }^{4,27}$ This might be the reason for the low overall prevalence of colonic adenoma in mainland Chinese according to our current data, as colonic adenoma is age-dependent.

The current guidelines do not endorse colorectal cancer screening at age $\geq 75$ years. ${ }^{28}$ Our results suggest an increase in age for both sexes is associated with an increased rate of adenoma (Figure 4$)$ and advanced adenoma $(P<0.001$; Figure 6). The rate of adenoma and advanced adenoma reached peak prevalence of $27.3 \%$ (Figure 4 ) and $8.0 \%$ (Figure 6), respectively, in patients aged $\geq 65$ years. These results were consistent with previous reports. ${ }^{4,10,27}$ Corley et a ${ }^{4}$ and Lieberman et $\mathrm{al}^{27}$ reported that adenoma and large-polyp prevalence continued to increase with age, including patients older than 75 and 80 years. Therefore, colonoscopy screening might be justified in the elderly, depending on comorbid conditions and life expectancy. ${ }^{27}$ When stratified by colonoscopy indication, the relationship between prevalence of adenoma and advanced adenoma and association with sex and age was similar in different subgroups (Figures 5 and 7).

The current guidelines ${ }^{28}$ recommend initiation of screening at age 50 years for all average-risk men and women, though growing evidence indicates that the prevalence of adenoma and advanced adenoma is higher in men than women., ${ }^{4}$ When using adenoma prevalence in men aged 45-49 years (13.1\%) as the benchmark, our study showed that women had a similar risk at age $55-59$ years (10.8\%; Figure 4$)$. Similarly, when using advanced-adenoma prevalence in men aged 45-49 years (3.4\%) as the benchmark, women had a similar risk at age $55-59$ years (2.6\%; Figure 6$)$. These results are in 
agreement with previous reports. ${ }^{24,29}$ Therefore, as suggested by Regula et al, ${ }^{24}$ if the recommended age at first screening is 50 years for men, initiation of screening might be safely delayed until age 60 years for women.

As expected, our multivariable logistic regression analysis indicated male sex and age were independent risk factors for both adenoma and advanced-adenoma prevalence. These results are consistent with Corley et $\mathrm{al}^{4}$ that adenoma prevalence increases substantially with age in both sexes and is much higher in men at all ages. A systematic review ${ }^{30}$ of 17 studies suggested men were more prone to advanced neoplasia and colorectal cancer across all age-groups of $40-70$ years. The sex effects on adenoma pathogenesis were unclear, though it is now becoming widely recognized that there are important sex differences in many diseases. ${ }^{31}$ These differences include rates of disease incidence, symptoms, and age of onset. A growing body of evidence shows that there are some sex-associated differences in gut bacterial flora composition and gut luminal metabolic activity. ${ }^{32}$ SankaranWalters et $\mathrm{al}^{33}$ found that women had higher baseline levels of immunoactivation compared to their male counterparts, thus predisposing them to inflammation-associated diseases that were exacerbated following menopause. Morrow ${ }^{31}$ suggested these important sex differences in disease can be seen as a subset of the more general phenomenon of sexual dimorphism of quantitative phenotypes apart from classical differences in circulating hormones.

The anatomic location of polyps and adenomas varies worldwide, depending on geographic predisposition and genetic differences in various populations. Our results indicated that most adenomas were located in the distal colon $(1,356$ of $2,287,59.3 \%)$, followed by the proximal (566 of $2,287,24.7 \%$ ) and bilateral colon (365 of 2,287, 16.0\%; Table 1). This is in line with a previous observation from Taiwan that the anatomic location of polyps and adenoma was predominantly left-sided in Chinese (58.6\%). ${ }^{7}$ Colonoscopy surveys from Romania ${ }^{34}$ and France ${ }^{35}$ also reported a preponderance of distal colon adenoma. In contrast, Ashktorab et $\mathrm{al}^{23}$ found that adenomas exhibited a predominantly proximal colonic distribution among Hispanics (53.7\%). Nouraie et $\mathrm{al}^{36}$ and Thornton et $\mathrm{al}^{37}$ reported that most colon polyps are right-sided in African-Americans. In addition, it was also noted that the odds of having proximal polyps was higher in African-Americans (OR 1.30, 95\% CI 1.11-1.52) compared to Caucasians. ${ }^{37}$ This diversity might be a result of genetic or environmental factors. Our study showed a higher proportion of polyps were adenomatous in the bilateral $(70.6 \%)$ and proximal $(58.8 \%)$ colon compared to the distal
$(51.8 \%)$ colon $(P<0.001$; Table 1$)$. In addition, multivariate logistic regression analysis indicated that location in the proximal colon (OR 1.41, 95\% CI 1.20-1.66; $P<0.001$ ) was independently associated with an increased risk of adenomas after adjustment for sex and age. These results were in line with Boroff et al, ${ }^{18}$ where a higher proportion of polyps were adenomatous in the right and proximal colon compared to the distal colon for all colonoscopy indications. It is suggested that the proximal colon is the seat of high bacterial activity, and is thought to participate in the creation of stressful conditions for the colon mucosa. ${ }^{23}$ Dejea et $\mathrm{al}^{38}$ found that colon biofilms, dense communities of bacteria encased in a likely complex matrix that contacts the colon epithelial cells and might enhance epithelial permeability, increasing direct access of bacterial antigens of mutagens to an unshielded epithelial surface and promoting procarcinogenic tissue inflammation, are nearly universal on right-colon tumors (adenoma and colorectal cancer). In addition, hypermethylation and microsatellite instability were more common in right-colon tumors compared to left-colon tumors. ${ }^{39}$ When stratified by colonoscopy indication, findings of comparisons between adenomatous polyps and nonadenomatous polyps were similar in different subgroups (Tables 2 and 3 ).

With respect to the anatomic location of advanced adenoma, it was clear that most advanced adenomas were located in the distal colon (365 of 592, 61.7\%; Table 4). Current medicolegal regulation in mainland China does not support the use of sigmoidoscopy as a screening test, though most advanced adenomas are located in the distal colon. On the other hand, we found that the distal $(26.9 \%)$ colon had a higher proportion of advanced adenoma compared to the proximal $(13.1 \%)$ colon (Table $4 ; P<0.001)$. Multivariate logistic regression analysis indicated that after adjustment for sex and age, location in the proximal colon (OR 0.56, 95\% CI $0.36-0.86 ; P=0.009)$ was associated with a significant reduction (44\%) in the risk of advanced adenoma compared with the distal colon. Research has suggested that molecular, pathological, and clinical features of colorectal neoplasia differ by anatomic location. ${ }^{40}$ Sawhney et $\mathrm{al}^{41}$ found that adenomas with high-grade dysplasia and early adenocarcinoma in the proximal colon were almost four times as likely to be sessile than those in the distal colon, though it has been reported that the prevalence of serrated adenomas was very low $(0.9 \%)$ in a Chinese population. ${ }^{15}$ The usual pathogenesis of colorectal cancer is an adenomatous polyp that slowly increases in size, followed by dysplasia and finally cancer. ${ }^{28}$ Therefore, it is assumed that adenomas in the proximal colon might have a slower speed of progression to advanced tumors 
than in distal colon. When stratified by colonoscopy indication, findings of comparison among advanced adenomatous polyps and unadvanced adenomatous polyps were similar in different subgroups (Tables 5 and 6).

Most advanced adenomas (491 of 592, 82.9\%) in our study were $>1 \mathrm{~cm}$ (Table 4). Sawhney et $\mathrm{al}^{41}$ also reported that almost $80 \%$ of advanced adenomas in their study were $>1 \mathrm{~cm}$. These results support previous assertions that polyps $>0.9 \mathrm{~cm}$ could be used as a surrogate study end point for advanced neoplasia. ${ }^{10,27}$ Chaput et $\mathrm{al}^{35}$ reported that polyp size was the only identified risk factor for advanced adenoma among polyps $<10 \mathrm{~mm}$. As expected, our results suggested that patients with larger polyps showed a higher proportion of adenoma and advanced adenomas (Tables 1 and 4). Multivariable logistic regression suggested that the size of polyps was associated with an increased risk of adenoma (OR 1.50, 95\% CI 1.44-1.56) and advanced adenoma (OR 2.78, 95\% CI 2.55-3.03) after adjustment for sex and age. As to number of polyps, our study showed the proportion of patients with two or more polyps was higher in those with advanced adenomatous polyps than those without advanced adenomatous polyps, though multivariable logistic regression failed to identify it as an independent risk factor for advanced adenoma, which is consistent with previous research. ${ }^{23}$

To the best of our knowledge, this is the first study with a large sample size to investigate the prevalence of colonic adenoma and advanced adenoma in a Chinese population stratified by age and sex in mainland China. Limitations of this study include potential confounding variables, such as diet, smoking, alcohol consumption, exercise, obesity, and aspirin use, ${ }^{4}$ which were not adjusted for when performing multivariate logistic regression analysis, due to lack of data availability. It would be interesting to incorporate these risk factors in future studies, in order to better stratify risks for colorectal cancer screening. Secondly, similarly to Boroff et al, ${ }^{18}$ we included colonoscopies for different indications (including screening and symptomatic patients) in thiscross-sectional study, rather than using data from screening colonoscopies exclusively. Though utilizing a mixed cohort of consecutive patients might reflect better what is encountered in general practice, ${ }^{18}$ our study demonstrated that a screening indication had the effect of decreasing adenoma-detection rates. Our hospital-based study results might not be generalizable for a healthy population. Also, our results were from a single center in a medium-sized city of China, which might not be generalizable to the entire Chinese population in mainland China.

In summary, the prevalence of colonic adenoma and advanced adenoma is lower in mainland China than in
Western countries. Age and sex were independent risk factors for the prevalence of adenoma and advanced adenoma. The optimal starting age for screening might differ by 10 years among men and women. Polyp size was associated with an increased risk of both colonic adenoma and advanced adenoma after adjustment for sex and age. Proximal colon polyps were a risk factor for adenoma, but associated with a significant reduction in the risk of advanced adenoma compared to the distal colon after adjustment for sex and age.

\section{Author contributions}

All authors contributed to data analysis, drafting, and critically revising the paper, and agree to be accountable for all aspects of the work. All authors read and approved the manuscript.

\section{Disclosure}

The authors report no conflicts of interest in this work.

\section{References}

1. Sung JJ, Chan FK, Leung WK, et al. Screening for colorectal cancer in Chinese: comparison of fecal occult blood test, flexible sigmoidoscopy, and colonoscopy. Gastroenterology. 2003;124(3):608-614.

2. Liu S, Zheng R, Zhang M, Zhang S, Sun X, Chen W. Incidence and mortality of colorectal cancer in China, 2011. Chin J Cancer Res. 2015;27(1):22-28.

3. Almadi MA, Alharbi O, Azzam N, Wadera J, Sadaf N, Aljebreen AM. Prevalence and characteristics of colonic polyps and adenomas in 2654 colonoscopies in Saudi Arabia. Saudi J Gastroenterol. 2014;20(3):154-161.

4. Corley DA, Jensen CD, Marks AR, et al. Variation of adenoma prevalence by age, sex, race, and colon location in a large population: implications for screening and quality programs. Clin Gastroenterol Hepatol. 2013;11(2):172-180.

5. Heitman SJ, Ronksley PE, Hilsden RJ, Manns BJ, Rostom A, Hemmelgarn BR. Prevalence of adenomas and colorectal cancer in average risk individuals: a systematic review and meta-analysis. Clin Gastroenterol Hepatol. 2009;7(12):1272-1278.

6. Aswakul P, Prachayakul V, Lohsiriwat V, Bunyaarunnate T, Kachintorn U. Screening colonoscopy from a large single center of Thailand: something needs to be changed? Asian Pac J Cancer Prev. 2012;13(4):1361-1364.

7. Liu HH, Wu MC, Peng Y, Wu MS. Prevalence of advanced colonic polyps in asymptomatic Chinese. World J Gastroenterol. 2005;11(30):4731-4734.

8. Hassan C, Repici A, Zullo A, Kanakadandi V, Sharma P. Colonic polyps: are we ready to resect and discard? Gastrointest Endosc Clin N Am. 2013;23(3):663-678.

9. Rex DK, Petrini JL, Baron TH, et al. Quality indicators for colonoscopy. Am J Gastroenterol. 2006;101(4):S16-S28.

10. Lieberman DA, Holub JL, Moravec MD, Eisen GM, Peters D, Morris CD. Prevalence of colon polyps detected by colonoscopy screening in asymptomatic black and white patients. JAMA. 2008;300(12):1417-1422.

11. Hong W, Dong L, Zippi M, et al. Colonic diverticulosis is not a risk factor for colonic adenoma. Ther Clin Risk Manag. 2018;14:531-537.

12. Corley DA, Jensen CD, Marks AR, et al. Adenoma detection rate and risk of colorectal cancer and death. NEngl JMed. 2014;370(14):1298-1306.

13. Lieberman D, Moravec M, Holub J, Michaels L, Eisen G. Polyp size and advanced histology in patients undergoing colonoscopy screening: implications for CT colonography. Gastroenterology. 2008;135(4):1100-1105.

14. Hong W, Geng W, Wang C, et al. Prevalence of colonic diverticulosis in mainland China from 2004 to 2014. Sci Rep. 2016;6:26237. 
15. Leung WK, Tang V, Lui PC. Detection rates of proximal or large serrated polyps in Chinese patients undergoing screening colonoscopy. $J$ Dig Dis. 2012;13(9):466-471.

16. Ashktorab H, Panchal H, Shokrani B, et al. Association between diverticular disease and pre-neoplastic colorectal lesions in an urban African-American population. Digestion. 2015;92(2):60-65.

17. Peery AF, Martin CF, Levinson SE, Sandler RS. Colonic diverticula are not associated with an increased risk of colorectal adenomas. Am J Gastroenterol. 2015;110(12):1694-1697.

18. Boroff ES, Gurudu SR, Hentz JG, Leighton JA, Ramirez FC. Polyp and adenoma detection rates in the proximal and distal colon. Am J Gastroenterol. 2013;108(6):993-999.

19. Kumbhari V, Behary J, Hui JM. Prevalence of adenomas and sessile serrated adenomas in Chinese compared with Caucasians. J Gastroenterol Hepatol. 2013;28(4):608-612.

20. Ptrend: Stata module for trend analysis for proportions. 2014. Available from: https://econpapers.repec.org/software/bocbocode/s426101.htm. Accessed June 25, 2018.

21. Cuzick J. A Wilcoxon-type test for trend. Stat Med. 1985;4(1):87-90.

22. National Cancer Institute. World (WHO 2000-2025) standard. Available from: https://seer.cancer.gov/stdpopulations/world.who.html. Accessed June 25, 2018.

23. Ashktorab H, Laiyemo AO, Lee E, et al. Prevalence and features of colorectal lesions among Hispanics: a hospital-based study. World $J$ Gastroenterol. 2015;21(46):13095-13100.

24. Regula J, Rupinski M, Kraszewska E, et al. Colonoscopy in colorectalcancer screening for detection of advanced neoplasia. $N$ Engl J Med. 2006;355(18):1863-1872.

25. Strul H, Kariv R, Leshno M, et al. The prevalence rate and anatomic location of colorectal adenoma and cancer detected by colonoscopy in average-risk individuals aged 40-80 years. Am J Gastroenterol. 2006;101(2):255-262.

26. Chen HM, Yu YN, Wang JL, et al. Decreased dietary fiber intake and structural alteration of gut microbiota in patients with advanced colorectal adenoma. Am J Clin Nutr. 2013;97(5):1044-1052.

27. Lieberman DA, Williams JL, Holub JL, et al. Race, ethnicity, and sex affect risk for polyps $>9 \mathrm{~mm}$ in average-risk individuals. Gastroenterology. 2014;147(2):351-358.

28. Qaseem A, Denberg TD, Hopkins RH, et al. Screening for colorectal cancer: a guidance statement from the American College of Physicians. Ann Intern Med. 2012;156(5):378-386.
29. Choe JW, Chang HS, Yang SK, et al. Screening colonoscopy in asymptomatic average-risk Koreans: analysis in relation to age and sex. $J$ Gastroenterol Hepatol. 2007;22(7):1003-1008.

30. Nguyen SP, Bent S, Chen YH, Terdiman JP. Gender as a risk factor for advanced neoplasia and colorectal cancer: a systematic review and meta-analysis. Clin Gastroenterol Hepatol. 2009;7681(6):676-681. e1-e3.

31. Morrow EH. The evolution of sex differences in disease. Biol Sex Differ. 2015;6:5.

32. Bolnick DI, Snowberg LK, Hirsch PE, et al. Individual diet has sex-dependent effects on vertebrate gut microbiota. Nat Commun. 2014;5:4500.

33. Sankaran-Walters S, Macal M, Grishina I, et al. Sex differences matter in the gut: effect on mucosal immune activation and inflammation. Biol Sex Differ. 2013;4:10.

34. Visovan II, Tantau M, Ciobanu L, Pascu O, Tantau A. Increasing prevalence of right-sided colonic adenomas in a high-volume endoscopy department in Romania: implications for colorectal cancer screening. J Gastrointestin Liver Dis. 2014;23(2):147-151.

35. Chaput U, Alberto SF, Terris B, et al. Risk factors for advanced adenomas amongst small and diminutive colorectal polyps: a prospective monocenter study. Dig Liver Dis. 2011;43(8):609-612.

36. Nouraie M, Hosseinkhah F, Brim H, Zamanifekri B, Smoot DT, Ashktorab H. Clinicopathological features of colon polyps from AfricanAmericans. Dig Dis Sci. 2010;55(5):1442-1449.

37. Thornton JG, Morris AM, Thornton JD, Flowers CR, Mccashland TM. Racial variation in colorectal polyp and tumor location. J Natl Med Assoc. 2007;99(7):723-728.

38. Dejea CM, Wick EC, Hechenbleikner EM, et al. Microbiota organization is a distinct feature of proximal colorectal cancers. Proc Natl Acad Sci US A. 2014;111(51):18321-18326.

39. Cancer Genome Atlas Network. Comprehensive molecular characterization of human colon and rectal cancer. Nature. 2012;487(7407): 330-337.

40. Missiaglia E, Jacobs B, d'Ario G, et al. Distal and proximal colon cancers differ in terms of molecular, pathological, and clinical features. Ann Oncol. 2014;25(10):1995-2001.

41. Sawhney MS, Dickstein J, Leclair J, Lembo C, Yee E. Adenomas with high-grade dysplasia and early adenocarcinoma are more likely to be sessile in the proximal colon. Colorectal Dis. 2015;17(8):682-688.
Cancer Management and Research

\section{Publish your work in this journal}

Cancer Management and Research is an international, peer-reviewed open access journal focusing on cancer research and the optimal use of preventative and integrated treatment interventions to achieve improved outcomes, enhanced survival and quality of life for the cancer patient. The manuscript management system is completely online and includes

\section{Dovepress}

a very quick and fair peer-review system, which is all easy to use. Visit http://www.dovepress.com/testimonials.php to read real quotes from published authors. 